\title{
Artigos
}

Regina Aparecida Marques de Souza' Nair Terezinha Gonzaga Rosa de Oliveira ${ }^{2}$ Lene Cristina Salles da Cruz ${ }^{3}$

\section{A teoria histórico-cultural como possibilidade para o pensar e o agir docente na educação infantil: o triplo protagonismo entre a criança, o professor e a cultura}

\begin{abstract}
Resumo: Tendo em vista a criança pequena e a adequação das práticas dos (as) professores (as) da educação infantil, elencamos, neste texto, algumas reflexões sobre o atendimento à infância e à criança no âmbito das políticas públicas, com objetivo de discutir o protagonismo da criança, do professor e da cultura, como possibilidades no pensar e agir docente. A metodologia é qualitativa, com enfoque bibliográfico, documental e de campo. Apresentamos uma base teórica que pode contribuir com as práticas pedagógicas dos (as) professores (as), que atuam com as crianças de zero até seis anos. O texto foi organizado de acordo com a perspectiva da teoria históricocultural, que explica o desenvolvimento humano a partir das determinações sociais e culturais. Os resultados indicam que, por meio da teoria histórico-cultural, é possível desenvolver a cultura escrita com as crianças pequenas, respeitando a sua idade $e$ suas especificidades. Enfatizamos que não estamos aqui defendendo a alfabetização na Educação Infantil, mas a linguagem oral e escrita, articulada com as demais linguagens.
\end{abstract}

Palavras-chave: Educação infantil. Infância e criança. Teoria histórico-cultural.Cultura escrita.

\section{The historical-cultural theory as a possibility for the thinking and acting in the early childhood education: the triple protagonism between the child, the teacher and the culture}

Abstract: In view of the small child and adequacy in the practices of the teachers of Early Childhood Education, in this text, we list some reflections on the care of children and children in the scope of public policies, with objective of discussing the child's protagonism, of the teacher and of the culture, as possibilities in thinking and acting teacher. The methodology is qualitative, with bibliographical and documental focus and of field. We presented a theoretical base that can contribute with the (the) teachers' (the) pedagogic practices that act with the zero children up to six years. The text was organized in agreement with the perspective of the historical-cultural theory that explains the human development starting from the social and cultural determinations. The results indicate that, through the historical-cultural theory, it is possible to develop the culture written with the small child, respecting his/her age and their specificities. We emphasized that we are not here defending the literacy in the infantile education, but the oral language and writing, articulate with the other languages.

Keywords: Child education. Childhood and child. Historical-cultural theory. Written culture

\footnotetext{
1 Doutora em Educação pela Universidade Estadual de Campinas. Professora Associada da Universidade Federal de Mato Grosso do Sul. E-mail: reginaamarques@hotmail.com

2 Mestre em Educação pela Universidade Federal de Mato Grosso do Sul. Campus do Pantanal. Coordenadora Pedagógica da rede municipal de ensino de Corumbá-MS. E-mail: nairtgr@hotmail.com

${ }_{3}^{3}$ Mestre em Educação pela Universidade Federal de Mato Grosso do Sul. Campus do Pantanal. Professora da rede municipal de ensino de Corumbá-MS.
} 


\section{Introdução}

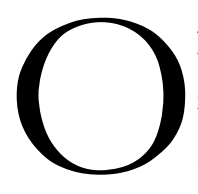

presente artigo resultado das nossas pesquisas de mestrado, estudos e discussões realizados no Grupo de Estudos e Pesquisas em Linguagem, Educação e Infância - Teoria HistóricoCultural/GEPLEI-THC/CNPq4. Tem como objetivo, discutir o protagonismo da criança, do professor e da cultura, como possibilidades no pensar e agir docente. Assim, pensando em sua aprendizagem e no seu desenvolvimento, convidamos você, leitor(a), pesquisador(a), professor(a), a discutir a apropriação da cultura escrita, em articulação com a educação infantil e o $1^{\circ}$ ano do ensino fundamental, que recebe crianças de $\operatorname{cinco}^{5}$ a seis anos nos contextos escolares.

Nosso maior desafio, nesta área, é apresentar a linguagem escrita por meio da cultura mais elaborada e por vivências com sentido e significado para a criança, sem the roubar à infância, que merece ser respeitada, pelo direito a "[...] uma educação que conduza a uma vivência de infância permeada de descobertas, brincadeiras e aprendizagens constantes" (ESPÍNDOLA; SOUZA, 2015, p. 51). Destacamos que não estamos aqui defendendo a alfabetização na Educação Infantil, mas o trabalho intencional do(a) professor(a) com a linguagem oral e escrita articulada com as demais linguagens.

No reconhecimento dos direitos da criança, vários movimentos, lutas e conquistas fizeram parte do cenário brasileiro, dentre eles, a Constituição Federal de 1988, que, no Brasil, representou um dos mais importantes acontecimentos em educação das crianças pequenas, por estabelecer as diretrizes, os princípios e as normas adotadas pelo País em relação a toda criança e, não apenas, à mãe trabalhadora.

Assim, levando em consideração a criança pequena, seus direitos e adequação nas práticas dos(as) professores (as), tanto da educação infantil quanto no $1^{\circ}$ ano do ensino fundamental, o estudo foi subsidiado pela teoria histórico-cultural, que explica o desenvolvimento humano a partir das determinações sociais e culturais, tendo em Lev SeminovichVigotski (1896-1934) um de seus principais representantes, bem como seus seguidores/colaboradores.

Por ser a metodologia de pesquisa qualitativa, com enfoque documental, bibliográfico e de campo, colhemos dados em documentos legais e oficiais, autores que preconizam a teoria histórico-cultural,

${ }^{4}$ Grupo de Estudos e Pesquisas em Linguagem, Educação e Infância - Teoria Histórico-Cultural, coordenado pela Professora Doutora Regina Aparecida Marques de Souza.

${ }^{5}$ Trazemos as crianças de cinco anos para nossa reflexão, porque em alguns estados do Brasil, especialmente, no estado de Mato Grosso do Sul, temos uma liminar e uma sentença proferidas pelo processo n. 001.07.041571-5, da Vara de Direitos e Fusos, Coletivos e Individuais, que autorizam o estado a matricular no primeiro ano do EF crianças que completam seis anos até o final do ano letivo, desconsiderando a legislação nacional, que estabelece o corte etário para a matrícula até o dia 31 de março. 
questionários e entrevistas semiestruturada com professoras que atuam com crianças pequenas, buscando compreender como se dá a relação entre a criança, o professor (a) e a cultura no espaço da educação infantil e no $1^{\circ}$ ano do ensino fundamental.

O texto foi organizado em três momentos. No primeiro, discutimos sobre o atendimento à infância e à criança no âmbito das políticas públicas, assim como a concepção de criança e infância na perspectiva da teoria Histórico-Cultural, que a concebe a criança como um ser ativo e protagonista no processo de aprendizagem e desenvolvimento.

No segundo, enfatizamos o triplo protagonismo entre a criança, o professor e a cultura sob a perspectiva da Teoria Histórico-Cultural, como possibilidades no pensar e no agir docente, que podem ser desenvolvidas nas práticas pedagógicas de professores (as) que atuam com as crianças de zero até seis anos, trazendo conceitos significativos, no tocante à infância, como condições necessárias à sua humanização.

E no terceiro, apresentamos alguns dados empíricos, obtidos na aplicação de questionários e entrevistas semiestruturadas, envolvendo professoras de Educação Infantil e docentes que atuam no $1^{\circ}$ ano do Ensino Fundamental. Professoras do $1^{\circ}$ ano do Ensino Fundamental, participantes do Programa de Formação Continuada Pacto Nacional pela Alfabetização na Idade Certa/PNAIC, expondo suas concepções e ações sobre o processo de Alfabetização e Formação de Leitores e Produtores de textos, em articulação com os estudos realizados no GEPLEI-THC e pesquisa de Mestrado $^{6}$, tendo como possibilidades o pensar e o agir docente, na perspectiva da Teoria Histórico-Cultural na educação das crianças pequenas.

\section{Infância e educação: a criança pequena como sujeito de direitos}

Discutir infância e educação impõe-nos vincular um olhar atento ao momento histórico em que se insere a infância na sociedade e, consequentemente, na educação. De acordo com Espíndola e Souza (2015, p. 48), a infância, ainda que pensada em um mesmo tempo, não é a mesma para todas as crianças, pois é marcada por várias questões:

\footnotetext{
Além da historicidade, a infância é marcada por questões de gênero, raça, etnia, religião e, especialmente, classe social [...] as crianças das camadas populares com certeza não vivem as mesmas experiências de infância que aquelas das camadas médias e das elites. $\mathrm{E}$ as crianças indígenas tampouco podem viver sua infância da mesma forma que uma criança branca, bem como as crianças afro descendentes, do campo, das florestas, as ribeirinhas (ESPÍNDOLA e SOUZA,2015, p. 48).
}

Todas as crianças têm infância, mas cada uma com a sua singularidade, suas vivências e historicidade. "Os diversos momentos históricos também irão definir formas diferentes de se ver a criança em sua relação com o mundo [...]”. (ESPÍNDOLA; SOUZA, 2015, p. 48).

Sob esse ponto de vista, antes de tratar do protagonismo entre a criança, o professor e a cultura sob a perspectiva da teoria histórico-cultural, que defendemos, tanto na educação infantil, quanto no

${ }^{6}$ Pesquisa de mestrado, defendida em 2017, na Universidade Federal de Mato Grosso do Sul/CPAN. 
ensino fundamental ( $1^{\circ}$ ano), vamos discutir alguns movimentos e documentos que dissertam sobre a educação das crianças pequenas e pequenininhas como sujeitos detentores de direitos.

Nos anos 1980, o Brasil testemunhou o protagonismo de vários movimentos sociais em defesa dos direitos da criança, que culminaram com a inclusão, na Constituição Federal de 1988, de artigos que a veem como sujeito de direitos. O documento estabeleceu a preocupação e a garantia de proteção integral à criança:

Art. 227 - É dever da família, da sociedade e do Estado assegurar à criança e ao adolescente, com absoluta prioridade, o direito à vida, à saúde, à alimentação, à educação, ao lazer, à profissionalização, à cultura, à dignidade, ao respeito, à liberdade, à convivência familiar e comunitária (BRASIL, 1988, p. 144).

A partir daí, a criança passou a assumir, em definitivo, o seu lugar na sociedade brasileira, especialmente na educação, pois o direito a uma vaga na educação infantil se estendeu da mãe trabalhadora para o direito de toda criança. Destacamos tal proposição, pois, em alguns municípios do nosso país, há uma distorção em relação ao atendimento da criança pequena na educação infantil, prevalecendo ainda à prioridade de uma vaga de zero até três anos, com a comprovação de trabalho em carteira assinada pela mãe ou o responsável pela criança, desconsiderando a Constituição Federal ${ }^{7}$

Após a Constituição de 1988, outros documentos foram criados para o entendimento da criança. Dentre eles, o Estatuto da Criança e do Adolescente (BRASIL, 1990), que, no Artigo 2º definiu "[...] a criança como a pessoa até os doze anos de idade incompletos". O documento lhe reconhece condições dignas. $\mathrm{Na}$ ascensão de seus direitos, novos questionamentos entraram em cena. Os movimentos neste sentido proliferaram. Especial atenção merece a Lei de Diretrizes e Bases da Educação Nacional (LDBEN), de n. 9.394/1996, nos artigos 29 e 30.

A evolução e o percurso histórico do entendimento do ser criança e sua infância mudam não só nos conceitos, mas principalmente na garantia de direitos. A inclusão da educação infantil na Lei de Diretrizes e Base da Educação Naciona/LDBEN n. 9.394/1996 respalda essa afirmativa, pois abandona a visão assistencialista a que eram submetidas às crianças e inserem objetivos e finalidades específicos para essa faixa etária.

Da LDBEN aos dias atuais, outros documentos surgem sob a forma de ver a criança, principalmente no processo de educação: os Parâmetros Curriculares Nacionais/PCN (1997), o Referencial Curricular Nacional para a Educação Infantil/RCNEI (1998), as Diretrizes Curriculares Nacionais para a Educação Infantil/DCNEIS (1999 e 2009) e a Base Nacional Comum Curricular /BNCC (2017).

No século XXI, diante dos tantos problemas socioeconômicos da população brasileira, a educação ocupa um papel fundamental na garantia das capacidades e direitos das crianças. Estudos e pesquisas nesta linha têm avançado em nosso país nos últimos anos, tanto no âmbito do conhecimento acumulado, como nas conquistas de direitos.

7 Não vamos aqui discutir tal temática, mas chamamos a atenção para o fato de ainda, em alguns municípios, se desconsiderarem os direitos da criança. 
O direito de ser criança, com suas múltiplas maneiras de ser e viver pode, às vezes, caminhar em direção contrária à do direito de ter uma educação que respeite suas especificidades. A ação pedagógica deve garantir à criança os seus direitos, principalmente o de ser criança, preservando sua identidade social, suas necessidades de aprender e de se apropriar da cultura. Dentre tais necessidades, destacamos a da cultura escrita, em seus aspectos lúdico e contextualizado.

Assim, diante dessas considerações, com a intenção de compreender a criança como um ser ativo e protagonista no processo de aprendizagem e desenvolvimento, explicitamos as concepção de criança para a teoria histórico-cultural.

Nos estudos de Leontiev (1978), o homem nasce animal e se humaniza pelas relações sociais; por meio do trabalho, transforma a natureza e é por ela transformado. Estabelece o início do seu desenvolvimento através das leis sociais e históricas, e não por fatores biológicos. Para compor tal defesa, Asbarh e Nascimento (2013) apontam que na compreensão da criança, para a teoria histórico-cultural, o primeiro aspecto a ser realçado é o entendimento de que a criança não é um adulto em miniatura. Sendo que, as transformações no desenvolvimento das crianças ocorrem por sua inserção no mundo histórico, social e cultural, não pelo processo natural do desenvolvimento, como alguns/algumas professores (as) acreditam.

De acordo com Mello e Farias (2010a), a concepção da criança como ser capaz de aprender é condição para que o(a) professor(a) procure novos recursos dentro e fora da instituição educativa e/ou escolar, na perspectiva de ampliar suas ideias e iniciativas:

A concepção de criança capaz de se relacionar com a cultura e com a natureza, capaz de interpretá-la e deaprender, atribuindo ao que se aprende um sentido pessoal - que não precisa ser certo do ponto de vista do conhecimento científico, [...], uma vez que para isso, a criança terá ainda muito tempo para aprender - é chave nesse processo (MELLO; FARIAS 2010a, p. 64).

Assim a teoria histórico-cultural define a criança como sujeito ativo, capaz de se relacionar com o mundo histórico e social e com a cultura acumulada. Souza (2007, p. 133) declara que a criança só se desenvolve, isto é, se humaniza, mediante a apropriação da cultura e no processo de sua atividade. Isto acontece, segundo a autora, mediante a apropriação da cultura, por seus processos de vida e educação, por meio das relações sociais e das instituições educativas.

Diante dessa complexidade de desafios e mudanças na compreensão da criança e da infância na trajetória das políticas educacionais, surgiram recentemente reflexões, discussões e debates gerados por diferentes posicionamentos e dúvidas sobre a ampliação do ensino fundamental de nove anos e a inclusão das crianças de seis anos nessa modalidade de ensino. Para Kramer, o fato merece atenção especial:

Ressalte-se desenvolvimento que o ingresso dessas crianças no ensino fundamental não pode constituir uma medida meramente administrativa. É preciso atenção ao processo de aprendizagem delas, o que implica conhecimento e respeito às suas características etárias, sociais, psicológicas e cognitivas (KRAMER, 2017, p. 6).

Pensando na aprendizagem e no desenvolvimento das crianças de seis anos de idade, respeitando suas características etárias, sociais, psicológicas e cognitivas no ensino fundamental, o Ministério de 
Educação (MEC), por meio da Secretaria de Educação Básica (SEB) e do Departamento de Políticas de Educação Infantil e Ensino Fundamental (DPE), fomentou debates com professores (as) e gestores (as) sobre a infância na educação básica, resultando no documento oficial Ensino Fundamental de Nove Anos- Orientações Gerais (BRASIL, 2010), que põe a criança e a infância em destaque no momento de sua inserção aos seis anos no ensino fundamental.

Antes de refletirmos sobre tais questões, sublinhamos que a mudança na estrutura do ensino fundamental não se deve referir ao que fazemos nos primeiros anos. É o momento para repensar toda a educação básica, desde os primeiros anos da educação infantil até os quatro anos finais do ensino fundamental. Sendo assim, os (as) professores (as) devem favorecer a criação de um ambiente educativo/escolar, que possa oportunizar à infância ser vivida em toda a plenitude, fazendo dela um espaço e um tempo de encontro do ser criança dentro e fora da instituição educativa.

\section{O triplo protagonismo entre a criança, o (a) professor (a) e a cultura: elementos que preconizam a aprendizagem e o desenvolvimento infantil}

Antes de iniciarmos este item, gostaríamos de explicitar a opção pelo termo protagonista na perspectiva da teoria histórico-cultural. De acordo com Mello (2010b), a cultura, o professor e a criança são os três elementos que participam do desenvolvimento humano. A autora os considera essenciais ao desenvolvimento:

A cultura é vista como fonte das qualidades humanas criadas ao longo da história pela atividade humana no mesmo processo em que foram criados os objetos materiais e não materiais que constituem a herança cultural da humanidade (Vigotski, 1994). O mediador apresenta a cultura para as novas gerações, e faz isso a partir do acesso que ele próprio tem a essa herança cultural, histórica e socialmente acumulada, do sentido que atribui à cultura e das concepções que orientam seu pensar e agir, em especial, nesse caso, o conceito de criança. A criança é o terceiro elemento ativo que condiciona essa relação dialética que resulta na humanização (MELLO, 2010b, p. 335).

Tanto para a autora quanto para a teoria histórico-cultural, os três componentes são fundamentais no desenvolvimento da criança. Assim, pensando na aprendizagem e no desenvolvimento da criança pequena, convidamos você, leitor (a), pesquisador (a), professor (a), a discutir esse protagonismo conosco.

O termo protagonismo, de acordo com o dicionário Houaiss, vem do grego, composto do prefixo "proto" (primeiro) e "agonistés" (combatente ou ator dramático). Assim, podemos compreender o termo protagonismo para as três categorias: criança, professor (a) e cultura. Trata-se de uma perspectiva que nos permite ver sob outra ótica a criança, assim como a da instituição educativa e escolar.

Falar em protagonismo é oportunidade para destacar nossa concepção de criança, sujeito social e histórico, detentora de direitos, que produz cultura e nela é influenciada por meio de instrumentos culturais. São sujeitos marcados pelas contradições sociais em que estão inseridas, mas também por um processo de humanização. As crianças estão em um processo de apropriação do mundo a partir do seu contato com o outro, mais experiente, e por uma das atividades que as envolvem por inteiro, que é a brincadeira. 
Percebemos, então, que a brincadeira é para elas fonte de aprendizagem e desenvolvimento, principalmente em sua educação quando pequenas. Também oferece momentos de interações sociais entre elas, seus pares e os adultos. De acordo com Prestes (2010, p. 158), "[...] o primordial na brincadeira é que ela reflete a vida; a criança brinca em situações reais que podem ser vividas na vida real naquele momento".

Na discussão sobre a infância nas instituições educativas, é imprescindível encontrar o sentido de solidariedade e estabelecer laços de caráter afetivo, ético, social e político. É relevante conduzir uma revisão do trabalho pedagógico dos (as) professores (as) que atuam com as crianças da educação infantil e as do $1^{\circ}$ ano do ensino fundamental, com cinco ou seis anos de idade. As crianças oriundas da educação infantil merecem respeito em suas especificidades.

Com a proposta do governo, devemos pensar e repensar as concepções de infância e o perfil do (a) professor (a) para atuar com elas nesses dois níveis. Para se atentar à individualidade da criança na vida escolar, requerem-se planejamento e diretrizes norteadoras quanto a seus aspectos físico, psicológico, intelectual e social, além de metas para o aumento do atendimento com garantia de qualidade. É determinante ter uma instituição infantil/escolar que seja um espaço e um tempo de aprendizado, de socialização, de vivências culturais, de desafios, de prazer e de alegria, enfim, de desenvolvimento do ser humano em todas as suas dimensões, na busca completa do ser humanizado.

De acordo com Mello (2010b), o compromisso com o máximo desenvolvimento das qualidades humanas nas crianças exige apropriação de uma teoria que perceba o papel da educação que desenvolve e humaniza.

As experiências vividas pelas crianças no meio influem sobre o seu desenvolvimento. Tais experiências acontecem na interação com outras pessoas e no seio da herança cultural em que estão inseridas. A relação entre aprendizagem e desenvolvimento é central para a prática pedagógica, porque nos remete a questões relacionadas ao que ensinar, a como ensinar e por que ensinar, afirmam Asbarh e Nascimento (2013).

Cabe à educação escolar ampliar o desenvolvimento da criança a partir da sua organização adequada, de modo que produza conhecimento. Os conteúdos devem ser organizados para formar nela aquilo que ainda não está formado, ampliando os níveis superiores do desenvolvimento, razão da preocupação do trabalho com a cultura mais elaborada. A família, a escola e os (as) professores (as) desempenham papel decisivo no processo de formação humana. Esses elementos são importantes para a sua aprendizagem e desenvolvimento por meio das vivências.

No tocante ao (a) professor (a), assume a função primordial de organizador (a) das ações, pois é aquele (a) que deve organizar o ambiente, as ações e momentos de aprendizagens, elaborados a partir de uma ação pensada e refletida para guiar/nortear o desenvolvimento. Disto decorre que, por aprender algo novo, a criança desenvolve suas capacidades intelectuais. 
A escola desempenha papel importante no desenvolvimento das crianças. Cabe ao(à) professor(a) organizar as vivências. De acordo com Vigotski:

\begin{abstract}
A vivência é uma unidade na qual, por um lado, de modo indivisível, o meio, aquilo que se vivencia está representado - a vivência sempre se liga àquilo que está localizado fora da pessoa - e, por outro lado, está representado como eu vivencio isso, ou seja, todas as particularidades da personalidade e todas as particularidades do meio são apresentadas na vivência, tanto aquilo que é retirado do meio, todos os elementos que possuem relação com dada personalidade, como aquilo que é retirado da personalidade, todos os traços de seu caráter, traços constitutivos que possuem relação com dado acontecimento (2010, p. 686).
\end{abstract}

A vivência é influenciada pelo meio no desenvolvimento psicológico e no desenvolvimento da personalidade da criança. Por meio das vivências, a criança apropria-se do mundo a partir das interações com o meio, num espaço educativo em que as pessoas envolvidas, sejam elas crianças ou professores (as), são concebidas como "[...] unidade indivisível da relação que se estabelece entre eles e que se constitui na vivência" (MELLO, 2010c, p. 730). Nesse movimento dialético, ou seja, no triplo protagonismo entre professor, criança e objetos da cultura, a criança aprende e se desenvolve.

Pela teoria histórico-cultural o triplo protagonismo abarca elementos importantes: o(a) professor(a), por organizar as experiências para a criança, responsável pela realização das atividades; a criança, por atuar no desenvolvimento da atividade; e os objetos culturais, introduzidos de forma dinâmica, de modo que a criança seja afetada por eles e deles se aproprie.

Nessa relação, o (a) professor (a) deve ser um (a) provocador (a) da aprendizagem e explorador (a) dos conceitos que a criança traz para o espaço educativo e escolar, contribuindo com o processo de apropriação de conceitos científicos e da produção social acumulada historicamente.

Precisamos oferecer à criança situações que lhe permitam a apropriação do conhecimento por meio do desenvolvimento da cultura. Conforme a teoria que estudamos o (a) professor (a) é responsável em garantir, os objetos culturais às crianças, para que possam se apropriar do conhecimento. Desse modo, é responsável por garantir, de maneira intencional, as necessidades vitais da criança. Nessa fase da educação, no processo de aprendizagem e desenvolvimento, o (a) professor (a) é o sujeito do processo de ensino e de aprendizagem, uma vez que organiza o uso dos objetos culturais que entram em cena. Esses objetos culturais, por sua vez, medeiam a aprendizagem das crianças a partir da intencionalidade do (a) professor (a).

Outro elemento que preconiza o desenvolvimento humano é a cultura. Por sua apropriação, o homem faz parte de um determinado momento histórico e ocupa um lugar na sociedade que produz os bens culturais. É na relação entre produção/apropriação de objetos culturais que o homem se forma como ser cultural, com capacidades e condutas culturais. Mello (1999) frisa que a tese central dos estudos de Vigotski e seus colaboradores contradiz a concepção de que a criança já nasce com potencialidades inatas que as condições de vida e educação vão ajudar a desenvolver. 
A compreensão do objeto a ser apropriado leva o (a) professor (a) a planejar várias formas de apresentar o objeto à criança, de modo que contribua com a atitude de leitora e produtora de textos. Mas em que consiste a formação dessas atitudes na criança pequena?

As atitudes, as capacidades, os gostos e as habilidades são produto da vivência dos indivíduos. Formar uma atitude leitora nada mais é do que educar a criança pequena para que cultive uma disposição favorável à construção desse conhecimento de forma realmente comprometida. Todas as ações do processo de ensino e aprendizagem devem, prioritariamente, atender a esse fim, dando sentido e significado a esse aprendizado. Caso contrário, corremos o risco de construir, em nossos educandos, abismos que dificultam a compreensão da escrita.

A compreensão e a valorização das funções sociais da escrita devem ter início na educação infantil, ou nos primeiros momentos da chegada da criança à escola, onde terá oportunidade de conviver com várias formas de linguagem. Quando nos referimos à educação infantil, não defendemos a alfabetização nessa etapa de ensino, mas um trabalho voltado às várias linguagens, tendo a escrita e a oralidade como práticas lúdicas e significativas a partir das vivências das crianças.

Mello (2012) defende que o trabalho com a escrita deve partir de uma significação:

O sentido que as crianças atribuirão à escrita será adequado se ele for coerente com a função social, coerente com o significado social da escrita. Podemos mostrar às crianças - por meio das vivências que proporcionamos envolvendo a linguagem escrita - que a escrita serve para escrever histórias e poemas, escrever cartas e bilhetes, registrar planos, intenções e acontecimentos, por exemplo. Por outro lado, podemos inserir as crianças em tarefas que envolvam a memorização de letras sem função social concreta... de fato, a escrita envolve a expressão de uma vontade de comunicação. Hoje é possível perceber que quando retiramos da escrita sua função social, dificultamos sua apropriação plena pelas crianças. Pois o contato com a linguagem escrita deve deflagrar a compreensão da mensagem escrita e não a associação de sons e letras (MELLO, 2012, p. 78).

Quando atribuímos significado ao conhecimento transmitido à criança, estamos favorecendo a construção de uma atitude leitora, que certamente traz significado à produção de textos. As instituições educativas e/ou escolares são esses espaços por excelência para esse aprendizado. Não são únicos, reconhecemos, mas fundamentais para incentivar na criança o gosto pela escrita e pela leitura.

Entretanto, mais importante do que decodificar letras, sílabas e palavras, é contribuir para a apropriação dessa formação. De acordo com Vygotski(1995), a escrita se forma por um sistema de signos que identificam, convencionalmente, os sons e as palavras da linguagem oral, que são, por sua vez, signos de objetos e relações reais. Mello acentua que a apropriação da escrita requer o foco na mensagem do texto:

[...] para o sujeito que lê ou escreve, o nexo intermediário representado pela linguagem oral desapareça e a escrita transforme em um sistema de signos que simbolizam diretamente os objetos e situações designadas. Pode-se compreender, a partir daí, que, para formar leitores e produtores de texto, o ensino da leitura deve focar a mensagem expressa pelo texto lido e não sons expressos por letras aí grafadas[...]. (MELLO, 2010b, p. 339). 
O sujeito que escreve deve manifestar seu desejo de expressão e não sons sem sentido em forma de letras. A escrita só terá sentido para a criança se for vinculada à sua função social, com a inserção da criança no mundo da cultura escrita, antes mesmo de chamar a atenção para o aspecto técnico, para o mecanismo da escrita (MELLO, 2010b).

Dessa forma, a criança, desde o início da educação básica, tanto na educação infantil, quanto no $1^{\circ}$ ano do ensino fundamental, deve ter acesso a diversas formas de linguagem, de modo que seja protagonista nesse processo e se aproprie da cultura escrita de maneira significativa.

De acordo com Vygotski (1995), a história da apropriação da escrita pela criança é a própria história do seu desejo de expressão - que começa pelo gesto, considerado pelo autor como escrita no ar, e se manifesta pelo desenho, pela fala, pelo faz de conta, chegando à linguagem escrita (MELLO, 2010b). Além dessas linguagens, Vigotski indica outras formas de expressão, como a pintura, a modelagem, a construção, a dança e a poesia, são essenciais na apropriação da escrita pela criança ao longo da sua vida escolar, que vai se tornando mais elaborada, manifestada de várias formas de representação e expressão.

Para Mello (2005), essas atividades são essenciais à formação da identidade, da inteligência e da personalidade da criança, além de constituírem as bases para a apropriação da escrita como um instrumento cultural complexo que, infelizmente, nas instituições escolares são concebidas como improdutivas. Para a autora, as concepções de educação infantil que dirigem as práticas de educação das crianças brasileiras entre três e seis anos são "muito fortes, sustentadas pela pressão dos pais, mas, sobretudo pela formação dos professores que trabalham com a Educação Infantil” (MELLO, 2005, p. 24). Tal escolarização ocupa o tempo da criança, tomando conta da brincadeira, do faz de conta e das conversas entre elas.

Tal prática de antecipação de escolarização sustenta-se na convicção de que, quanto mais cedo a criança se transformar em escolar e se apropriar da escrita, maiores as suas possibilidades de sucesso na escola e na vida, principalmente se essa apropriação for repassada no sentido técnico, sem reconhecer as diversas formas de linguagens, como as brincadeiras, o faz de conta, as conversas entre as crianças, com seus pares e com adultos. Somos contrárias a essa antecipação; concordamos com Mello (2012) quando evidencia a possibilidade de a escrita nascer da necessidade da criança e contribuir positivamente para a formação de leitores:

[...] esse movimento que resulta na formação de leitores e produtores de texto começa na educação infantil, quando lemos histórias, notícias de jornal, gibis, revistas, assuntos de interesse do grupo em enciclopédias e mesmo quando procuramos palavras desconhecidas do grupo de crianças em dicionários, quando as crianças em diferentes idades manipulam esses objetos portadores de textos. Acontece também quando usamos a escrita para registrar experiências vividas, comunicar aos outros essas experiências, para planejar e organizar a vida do grupo na sala, enfim, quando a escrita é utilizada pelo grupo em sua função social, o que quer dizer, cumprindo uma função verdadeira para a qual ela existe (MELLO, 2012, p. 83).

Como podemos verificar, a formação da atitude leitora e produtora de texto devem ser oportunizadas desde muito cedo na educação infantil, mas como forma natural da necessidade de escrever e ler as situações reais da vida. 
Antes de nos preocupar com a leitura e a escrita propriamente ditas, devemos atentar para as atividades significativas e com sentido para as crianças. Assim, a cultura escrita se constrói no meio social como resultado da mediação do homem com o mundo circundante, em que a escrita, segundo Vygotski (1995), é um sistema de representação simbólica da realidade, ou seja, produto cultural construído historicamente.

Quando inserida no ambiente educativo/escolar, com o objetivo de se apropriar da formação da atitude leitora e produtora de textos, a criança precisa participar de situações de escrita como função social, privilegiando o processo cultural, desde o seu ingresso na educação infantil até chegar ao ensino fundamental. Para Arena (2010), a importância do meio constituído pela cultura revela a necessidade de, desde o início, colocar em prática atitudes de ler,com noção clara de que ler é atribuir sentido por meio de sinais gráficos, em situações elaboradas de cultura humana.

O (A) professor (a) é responsável por organizar e apresentar as atividades para a criança, buscando estabelecer a relação entre o conhecimento que traz de casa e o conhecimento científico. As instituições educativas precisam valorizar tais conhecimentos e trabalhar a cultura escrita com sentido e significado com as crianças, e não "[...] por meio de treino e pelo desenho de letras" (ESPÍNDOLA; SOUZA, 2015, p. 50), para que não aprendam de uma forma artificial e descontextualizada, como aprendemos em nossas escolas e como ainda vivenciamos com nossas crianças.

\section{Da teoria a prática: formação de leitores (as) e produtores de texto na concepção das professoras e o entrelaçamento do triplo protagonismo na concepção da Teoria Histórico-Cultural}

$\mathrm{Na}$ intenção de compreendermos e analisarmos as concepções das professoras que atuam na educação infantil e no $1^{\circ}$ ano do ensino fundamental, sobre a formação de leitores e a apropriação da cultura escrita na educação da criança pequena, iniciamos em primeiro momento, os estudos teóricos. Em seguida, realizamos a pesquisa empírica, na intenção de coletar dados para compor o artigo.

A pesquisa concretizou-se nos anos de 2016 e 2017, em duas instituições públicas de educação, sendo uma creche e a outra, uma escola. Delimitamos o nosso campo empírico, e optamos por realizar questionários e entrevistas semiestruturadas com 5(cinco) professoras, sendo 2(duas) da educação infantil e 3(três) do $1^{\circ}$ ano do ensino fundamental, participantes do Programa de Formação Pacto pela Alfabetização na Idade Certa/PNAIC.

A primeira pergunta realizada às professoras da Educação Infantil, diz respeito à idade adequada para alfabetizar as crianças, sobre isso expomos alguns resultados:

"Existe e é a partir dos 5 anos, já pode iniciar a alfabetização de uma criança". (indivíduo - 3 - creche)

"Não há uma idade adequada, porque elas começam muitas vezes em casa essa alfabetização ou na Educação Infantil". (Indivíduo - 4 - escola). 
Nossa intenção em colocar esse questionamento como o primeiro se deu de forma proposital, pois a resposta dada pela professora pode, ou não, indicar sua concepção de alfabetização e os caminhos utilizados para se chegar a esse fim. As respostas apresentadas denunciam que, as discussões sobre a alfabetização, enquanto processo de aprendizagem da leitura e da escrita, ainda é um tema controverso no cenário da educação. Não existe um consenso por parte das professoras a respeito da idade para o inicio desse processo.

A segunda resposta apresentada foi a que mais nos trouxe preocupação, uma vez que, admite que não há idade para se alfabetizar uma criança, e diante dos nossos estudos, constatamos que aprender a ler e escrever é uma atividade complexa para a criança, pois antes de aprender a ler e escrever, ela precisa vivenciar todas as experiências envolvendo as múltiplas linguagens infantis, para a partir daí, apropriar-se do conhecimento técnico da língua.

Em outro momento, foi questionado às entrevistadas o que elas entendem por formação de leitores e produtores de textos. As duas professoras da educação infantil relataram que para elas, formar leitores e produtores de textos na educação infantil, significa levar a criança a ler o mundo, com descobertas significativas e com função social. Para as docentes, a escola tem formado crianças leitoras no momento que trabalha a leitura e interpretação, desenvolve diversos gêneros textuais com as crianças, como: histórias, poemas, poesias, bilhetes, receitas, cantigas, contos, adivinhações e textos em tirinhas. Em relação a esse aspecto Mello afirma:

O sentido que as crianças atribuirão à escrita será adequado se ele for coerente com a função social, coerente com o significado social da escrita. Podemos mostrar às criançaspor meio de vivências que proporcionamos envolvendo a linguagem escrita - que a escrita serve para escrever histórias e poemas, escrever cartas e bilhetes, registrar planos, intenções e acontecimentos, por exemplo (MELLO, 2012, p.78).

As considerações de Mello evidenciam, a importância que precisa ser dada à construção de significados para a escrita, são esses significados que permitirá à criança construir uma aprendizagem concreta e significativa.

De acordo com as respostas das professoras da educação infantil é papel dos profissionais que atuam com as crianças pequenas, observarem e trabalharem o potencial dos alunos, para que saibam expressar oralmente e por escrito com clareza, sabendo pensar, falar, ouvir, dialogar e criticar. As referidas professoras afirmam que utilizam livros de literatura e jogos em suas salas, pois acreditam que esses recursos contribuem com a sua prática, porque servem de incentivo aos alunos em relação à aprendizagem e desenvolvimento das crianças. Trabalham várias estratégias de leitura e escrita, ressaltando que essas experiências auxiliam no desenvolvimento da atitude leitora e apropriação da cultura escrita das crianças.

Em relação às entrevistas semiestruturadas realizadas com as três professoras do $1^{\circ}$ ano do Ensino Fundamental, elencamos dois questionamentos: um relacionado à alfabetização proposta no PNAIC e outro sobre a formação de leitores e produtores de textos, para contextualizar nosso estudo. O primeiro direcionado as professoras do Ensino Fundamental, diz respeito à concepção de alfabetização. Para concretizar esse pensamento trazemos para discussão a opinião, de uma das entrevistadas: 
Eu acredito que seja por essa criança que a gente atende do $1^{\circ}$ ao $3^{\circ}$ ano, a par da cultura, do desenvolvimento, dar interesse nele para a leitura, não só a leitura do alfabeto e alfabético matemático, mas uma noção de mundo. Acho que esse é o principal objetivo do PNAIC (Professora Márcia - $1^{\circ}$ ano do Ensino Fundamental, entrevista, 2016).

Pelo depoimento da professora, o processo de alfabetização deve-se dar oportunidade de a criança participar de atividades culturais e experiências, de variadas formas, dando continuidade à história. Em nossos estudos sobre a Teoria Histórico-Cultural vimos que é significativo oferecer um universo cultural e experiências que conduzam a aprendizagem e o desenvolvimento, levando a criança ao processo de humanização e transformação.

De acordo com a Teoria Histórico-Cultural, o trabalho do (a) professor (a), “[...] deve garantir, com toda intencionalidade, a formação das faculdades que, na ausência dos processos de educação, não acontecerão", (MELLO, 2010, p. 198). Nesse processo, o (a) professor(a) é responsável por garantir as necessidades vitais da criança, de maneira intencional.

No que tange ao segundo questionamento: A formação do PNAIC possibilitou às crianças a apropriação da cultura escrita no processo de alfabetização? Desvelamos que as professoras alfabetizadoras desenvolvem diversas estratégias de leitura e escrita, como parlendas, músicas, receitas, trava-línguas, poemas, quadrinhas, regras de jogos, cantigas, adivinhações, cantigas, caça-palavras, bingo, palavras cruzadas, roda de leitura, dramatização, projetos, leitura deleite ${ }^{8}$ e sequência didática, registros de músicas e interpretações no processo de alfabetização e formação de atitude leitora nas crianças.

Em conformidade com as atividades relacionadas acima, temos o seguinte depoimento:

Com as atividades que envolvem leituras de diversos textos, como parlendas, quadrinhas, regras, jogos, cantigas, adivinhas, caça-palavras, bingo (sic), palavras cruzadas, roda de leitura, brincadeiras com cantigas de roda, dramatização, leitura e registro de músicas e interpretação, assim facilitando o processo de alfabetização (Professora- $1^{\circ}$ ano do Ensino Fundamental, entrevista 2016).

Desse modo, a maneira de trabalhar a escrita com as crianças do $1^{\circ}$ ano do ensino fundamental, a partir das estratégias utilizadas pelas professoras, está diretamente relacionada ao processo de formação, que vêm recebendo, através do Programa de Formação Continuada Pacto Nacional Pela Alfabetização na Idade Certa/PNAIC.

Diante dos depoimentos das professoras tanto da Educação Infantil, como do Ensino Fundamental, percebemos que todas desenvolvem diversos genêros textuais com as crianças. No entanto, devemos ter claro que o(a) professor(a), deve ser um(a) provocador(a) da aprendizagem e explorador(a) dos conceitos que a criança traz para o espaço educativo, contribuindo assim, com o processo de apropriação de conceitos científicos e apropriação da cultura escrita, promovendo sempre situações desafiadoras, para que as crianças aprendam e se desenvolvam, principalmente para "[...] ensinar o aluno a ler, como ato cultural, para criar sua própria leitura, nos limites de sua potencialidade, na sua relação com diferentes gêneros e suportes textuais" (ARENA, 2010, p. 243), possibilitando a formação dos modos de 
pensar cada vez mais elaborados, pois só assim haverá o triplo protagonismo entre a criança, o professor e a cultura.

Sendo assim, o (a) professor (a), deve vivenciar essas atividades com as crianças, desde a Educação Infantil até o Ensino Fundamental, de modo a garantir a aprendizagem e desenvolvimento dos pequenos com sentido e significado. De acordo com Mello (2010), compreender a linguagem escrita como instrumento cultural complexo implica rever as formas de apresentação dessa linguagem às crianças e almejar a formação de leitores (as) e produtores (as) de texto. A autora evidencia que, quando se introduz para a criança a linguagem escrita por seu aspecto técnico, ocorre um problema. As tarefas de escrita se tornam cansativas, tomando o tempo das atividades lúdicas. Em contrapartida, Leontiev (1988) considera a atividade lúdica como a principal forma de levar o conhecimento para a criança até os seis anos. Por meio dela a criança aprende mais e se desenvolve, porque as funções, nessa idade, estão em formação e desenvolvimento.

A partir das respostas das professoras, no tocante à formação, é possível perceber a importância da formação continuada, enquanto espaço de debate, de análises, problematizações e aprendizados, que podem refletir diretamente na qualidade da educação oferecida às crianças. Não vamos entrar no mérito de discussão do Programa de Formação PNAIC, mas reiteramos a necessidade e importância das formações para a constituição do ser professor.

\section{Considerações Finais}

Pelas discussões sobre a criança pequena, seus direitos e a teoria histórico-cultural e o triplo protagonismo entre a criança, o professor e a cultura, o nosso estudo revelou que ainda temos grandes desafios a enfrentar, pois sabemos que muitas crianças não conquistaram seus direitos, principalmente a uma educação que lhe respeite a infância e as especificidades, em especial as crianças inseridas no $1^{\circ}$ ano do ensino fundamental, com cinco a seis anos de idade. Crianças procedentes da educação infantil que precisam de uma educação permeada de descobertas, brincadeiras e aprendizagens significativas e com sentido.

Reconhecemos que muitas delas não estão sendo respeitadas em suas especificidades, principalmente no que diz respeito à apropriação da cultura escrita. Entendemos que "[...] a linguagem escrita articulada com a infância não é uma tarefa simples, porque, para alguns, aprender a escrever é o primeiro passo para a saída da infância" (ESPÍNDOLA; SOUZA, 2015, p. 51).São comuns, nas instituições infantis, espaços de brincadeiras, entretanto, ao ensino fundamental esses espaços não fazem parte do contexto, nem do planejamento do professor.

Preocupamo-nos, neste estudo, em apresentar a teoria histórico-cultural como possível caminho para desenvolver atividades mais elaboradas e vivências com sentido e significado para as crianças, promovendo a aprendizagem e o desenvolvimento junto a esses pequenos cidadãos, respeitando-lhes a infância e as especificidades. 
Após reflexões e entendimento sobre a concepção de infância, de criança e da linguagem escrita como instrumento cultural complexo, compreendemos que a articulação de três elementos - infância, criança e brincadeiras -, sob a perspectiva da teoria histórico-cultural, são indispensável à apropriação da linguagem escrita, principalmente para as crianças pequenas, sem lhes roubar a infância.

Expomos a criança como um ser sócio-histórico e cultural capaz, com potencial para aprender e desenvolver-se com as máximas qualidades humanas. Trouxemos reflexões, concepções e algumas ações das professoras, propondo caminhos para o desenvolvimento da cultura escrita nas crianças, tanto da educação infantil, quanto no $1^{\circ}$ ano do ensino fundamental, respeitando sua infância e especificidades, com propostas de escrita coerentes com a sua função e o seu significado social.

Enfim, apreendemos que a teoria histórico-cultural, aliada à prática pedagógica, fundamenta a apropriação da escrita e da leitura pela criança, excluindo a aplicação de atividades sem sentido e significado, pois almejamos uma educação de qualidade, tendo em mente o triplo protagonismo entre a criança, o (a) professor (a) e a cultura.

\section{Referências}

ASBARH, F. da S. F.; NASCIMENTO, C.P. Criança não é manga: não amadurece. Conceito de Maturação na teoria histórico-cultural. Psicologia: ciência e profissão. v. 33, n. 2, 2013.

ARENA, D.B. O Ensino do ato de ler e suas contradições. In: Ensino em Re-Vista, Uberlândia, 17 (1), jan./jun. 2010.

BRASIL. Referencial Curricular Nacional para a Educação Infantil. Brasília: MEC, 1998. 3v.

BRASIL.Diretrizes Curriculares Nacionais para a Educação Infantil. Brasília: MEC, 2010.

BRASIL.Estatuto da Criança e do Adolescente. Lei no 8.069/1990. Brasília-DF: Câmara dos Deputados: 1990.

BRASIL. Ensino Fundamental de Nove Anos-Orientações Gerais. Brasília: MEC, 2004.

BRASIL.Lei do Ensino Fundamental dos Nove Anos - Lei nº 11.114, de 2005.

BRASIL.Lei do Ensino Fundamental dos Nove Anos - Lei nº 11.274, de 2006.

BRASIL.Lei de Diretrizes e Bases da Educação Nacional: nº 9.394/1996. Brasília: 1996.

BRASIL.Base Curricular Comum Nacional. Brasilia: MEC 2017. 
BRASIl. Secretaria de Educação Básica. Diretoria de Apoio à Gestão Educacional. Pacto Nacional pela Alfabetização na Idade Certa. Ministério da Educação. Secretaria de Educação Básica. Diretoria de Apoio à Gestão Educacional - Brasília: MEC. SEB, 2012.

CRUZ. Lene Cristina Salles da.A apropriação da cultura escrita na educação da criança pequena: Desafios e possibilidades de uma prática docente.Dissertação (Mestrado em Educação) - Universidade Federal de Mato Grosso do Sul, Corumbá, 2017.

ESPINDOLA, Ana Lucia; SOUZA, Regina Aparecida Marques de. O lugar da cultura escrita na educação da criança: pode a escrita roubar a infância? In: BRASIL. Pacto Nacional pela Alfabetização na Idade Certa. A criança no ciclo de alfabetização. Caderno 2. Brasília: MEC, 2015. p. 47-55.

HOUAISS, Antonio. Dicionário eletrônico da Língua Portuguesa. Produzido e distribuído por Editora Objetiva Ltda. São Paulo, 2006.

KRAMER, Sonia. Infância e sua singularidade. In: BRASIL, Ensino fundamental de nove anos: orientações para a inclusão da criança de seis anos de idade. Brasília: Ministério da Educação, 2007.

LEONTIEV, A. N. Uma contribuição à Teoria do Desenvolvimento Infantil. In: VIGOSTSKII, L. S.; LURIA. A. R.; LEONTIEV. A. N. Linguagem, desenvolvimento e aprendizagem. São Paulo: Ícone, 1998. p. 59-84.

LUGLE, A. K. e MELLO, S. A. Produção de sentido para a linguagem escrita e formação da atitude leitora/autora.Revista Educação. PUC - Campinas, Campinas, 20 (3): 187-199, set./dez. 2015.

MELLO, Suely Amaral. Algumas Implicações Pedagógicas da Escola de Vygotsky para a Educação Infantil. Pro-Posições. Campinas, v.10, n.1, p. 16-27, 1999.

MELLO, S. A. O processo de aquisição da escrita na Educação Infantil: Contribuição de Vigotski. In: GOULART, A.L.; MELLO, S. A (Org.). Linguagens infantis: outras formas de leitura. Campinas, SP: Autores Associados, 2005.

MELLO, S. A. Ensinar e aprender a linguagem escrita na perspectiva histórico-cultural. Psicologia Política. v.10 n.20 São Paulo dez. 2010.

MELlO, S. A. e FARIAS, M. A. S. e. A Escola como Lugar da Cultura mais elaborada. Revista Educação. Santa Maria, v. 35, 2010a.

MELLO, Suely Amaral. Ensinar e aprender a linguagem escrita na perspectiva histórico-cultural. Psicologia Política. vol.10 n.20 São Paulo dez. 2010b. 
MELLO, Suely Amaral. A questão do meio da pedalogia e suas implicações pedagógicas. Psicologia USP, São Paulo, 2010c.

MELLO, SuelyAmaral. Letramento e alfabetização na Educação Infantil, ou melhor, formação da atitude leitora e produtora de textos nas crianças. In: VAZ, Alexandre Fernandez. MOMM, Caroline Machado (Orgs.). Educação infantil e sociedade: questões contemporâneas. Nova Petrópolis: Nova Harmonia, 2012.

OLIVEIRA. Nair Terezinha Gonzaga Rosa de. Pacto Nacional pela Alfabetização na Idade Certa no município de Corumbá/MS e o primeiro ano do ensino fundamental: As ações da formação na prática pedagógica. Dissertação (Mestrado em Educação) - Universidade Federal de Mato Grosso do Sul, Corumbá, 2017.

PRESTES, Zoia Ribeiro. Quando não é quase a mesma coisa: Análises de traduções de Lev SeminovitchVigotski no Brasil - Repercussões no campo educacional. Universidade de Brasília, Brasília, Tese de Doutorado, 2010.

SOUZA, Maria Cecília Braz Ribeiro de. A concepção de criança para o enfoque histórico-cultural. Universidade Estadual Paulista, Marília, SP, Tese de Doutorado, 2007.

VIGOTSKI, L. S. Quarta aula: a questão do meio na pedologia. Tradução de Márcia Pileggi Vinha. Revista Psicologia USP. São Paulo, 2010, 21(4), 681-701.

VYGOTSKI, L.S. El desarrollo del lenguaje escrito.Obras Escogidas. Madrid: Visor. V.3. 1995.

VYGOTSKI, L. S. A pré-história do desenvolvimento da linguagem escrita. Tradução por Suely Amaral Mello e Regina Aparecida Marques de Souza [do original VYGOTSKI, Lev Semenovich. La pre-historia del desarrollo del lenguaje escrito. In: VYGOTSKI, Lev Semenovich. Obras escogidas. Madrid: Visor, 1995. 3v.]. 2015. (mimeo). 